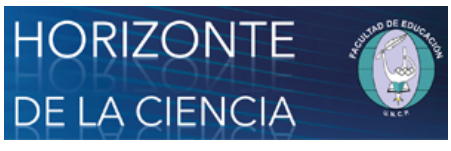

Horizonte de la Ciencia

ISSN: 2413-936X

horizontedelaciencia@uncp.edu.pe

Universidad Nacional del Centro del Perú

Perú

\title{
Un Cristo colonial en Huancavelica
}

Plasencia Soto, Rommel

Un Cristo colonial en Huancavelica

Horizonte de la Ciencia, vol. 9, núm. 16, 2019

Universidad Nacional del Centro del Perú, Perú

DOI: https://doi.org/10.26490/uncp.horizonteciencia.2019.16.470

(C) Los autores otorgan el permiso a compartir y usar su trabajo manteniendo la autoría del mismo.

Esta obra está bajo una Licencia Creative Commons Atribución-NoComercial 4.0 Internacional. 


\section{Un Cristo colonial en Huancavelica}

\section{Wankawillkachu huk colonial Kristu}

A COLONIAL CHRIST IN HUANCAVELICA

UM CRISTO COLONIAL EM HUANCAVELICA

Rommel Plasencia Soto

Universidad Nacional Mayor de San Marcos, Perú

plasenciasotor@gmail.com

DOI: https://doi.org/10.26490/

(D) http://orcid.org/oooo-6637-8431

\section{RESUMEN:}

En este artículo se muestra la aparición y culto de un cristo milagroso en una comunidad de Huancavelica. Dicha aparición se dio en el contexto de la evangelización religiosa en los Andes durante el periodo colonial. Además se presentan las bases sociales y simbólicas de dicha aparición y se la compara con otros "cristos" de la región.

Palabras Clave: Cristo, Huancavelica, Andes.

\section{Abstract:}

In this article, there appears and the cult of a miraculous Christ in Huancavelica's community. The above-mentioned appearance was given in the context of the religious evangelization in the Andes during the colonial period. In addition, they present some social and symbolic bases of the above appearance and she is compared with other "Christ's" of the region.

KEYWORDs: Christ, Huancavelica, Andes.

\section{Resumo:}

Neste artigo mostra-se a aparição e o culto de um Cristo milagroso em uma comunidade de Huancavelica. Dita aparição foi dada no contexto da evangelização religiosa nos Andes durante o período colonial. Além disso, eles apresentam as bases sociais e simbólicas da aparição e é comparada com outros "cristos" da região.

Palavras-chave: Cristo, Huancavelica, Andes.

Palabras clave Kristu, Wankawilka, ulukuna

\section{INTRODUCCIÓN}

El presente artículo tiene por objetivo mostrar al lector, algunos pormenores de la aparición en el siglo XVII, de un cristo con fama de milagroso en la región de Huancavelica. Dicha aparición empero, creemos fue parte de una estrategia general de evangelización religiosa en los Andes centrales. El cristo de Huayllay Grande se erigió además, en una zona matricial que implementó una concurrida feria y que al igual que otros santuarios (como pueden serlo el señor de Huamantanga o Qoyllur Riti) permitió articular a comunidades rurales, complementar espacios productivos y sobre todo, demarcar un "territorio con identidad".

La feria de Huayllay en ese sentido, articulaba no sólo a regiones de las partes bajas de la región de Angaraes (como la vecina provincia de Huanta), sino también los corredores mercantiles de las minas de Huancavelica y de Julcani. Con la independencia, rotos parcialmente estos circuitos y desactivada la protección colonial, los siglos XIX y XX serán testigos de la movilidad religiosa que otorgaba identidad colectiva a pueblos "blancos" e "indios". Fenómeno, que ocurre en toda la región: Moya, Pallalla, Huayllay, Julcamarca y Acoria por ejemplo, se verán envueltos en pugnas sociales y étnicas, disputándose los cristos, vírgenes y santos que no sólo -como repetimos- dotaban de identidad local a un mundo ya fragmentado (atomizado políticamente y disuelto 
étnicamente) sino que permitieron la renovación de nuevas fuentes de prestigio y de estatus en un escenario cada vez más involucrado con el mercado.

Aculturación

El anónimo de la "Descripción de la provincia de Angaraes" describía una imagen muy venerada en la región hacia el siglo XVII:

En el pueblo de Atun Huayllay veneran una imagen de Cristo Nuestro Señor Sacrificado muy devota, y no hace muchos años que, abriendo zanjas para la iglesia que hoy tienen, se hallan enterradas en ellas dos estatuas de piedra casi natural, que parecen ser el Apóstol Santiago, y en lo tosco de la una denota mucha antigüedad, y algunos les parece ser de antes de la conquista de este reino. (Jiménez de la Espada: 203).

Del mismo modo lo reportan ya tardíamente, Alcedo y Herrera (1967 II: 201) y el cosmógrafo Cosme Bueno (1951)[1] . Lo singular de la descripción hecha por el "Anónimo" es que confirma una idea muy arraigada en los españoles hacia mediados del siglo XVI, en el cual las creencias pre-hispánicas eran interpretas como inversiones de la religión cristiana (la parodia diabólica). Originalmente algún apóstol viajero (Santo Tomás o Bartolomé) viajarían por el continente americano y diseminado la semilla evangélica.

Esta propuesta pretendía confirmar una idea de evangelización prehispánica acunada por el Primer Concilio Limense, y que al decir de Estenssoro (2003) hizo "nacer una confianza en la conversión y una mirada tolerante y hasta de simpatía por el paganismo local" (199) a la vez que se "completaba la integración de los indios en la historia de la salvación" (196). Pero luego, los jesuitas al endurecer las exigencias rituales y las pruebas de una evangelización ortodoxa, propondrán (como Acosta) que el diablo aprovechando el relajamiento y abandono de los americanos, caricaturizará por analogía y remedo, los rituales cristianos (Acosta 1986).

Estos apóstoles viajeros fueron adorados y representados, y eso es lo que encontraron los artífices cuando se construyó el santuario de Huayllay Grande[2]. Las "estatuas de piedra" resultaron ser en realidad tal como lo explicaría Tello más adelante, monolitos wari.

Entonces desde el siglo XVII, esta imagen con fama de milagrosa, se constituyó en una feria y un circuito religioso que articuló a zonas campesinas y cuyo radio de acción alcanzaban hasta la lejana Andahuaylas y la provincia de Huanta.

Su esplendor fue decayendo desde la segunda mitad del siglo XX, por lo consolidación de nuevos distritos cuyo origen eran las comunidades campesinas de la zona y la hegemonía de Lircay como capital provincial y sede del poder local, que erigió como patrona del pueblo misti a la Virgen del Carmen.

Ahora abordaremos este complejo surgido en un contexto colonial, a través del plano simbólico relacionado con la evangelización cristiana de la "república de indios" y luego, de la estructura social erigida en torno a su culto y expresada en jerarquías cívicas y religiosas.

\section{El origen del Cristo}

Cuando Todorov acuña el término de "conquista hermenéutica" se refiere al hecho de que muchas sociedades conquistan y colonizan a otras, utilizando el propio utillaje cultural de los vencidos. Usan los códigos, principios y arreglos de esas mismas culturas, para hacer más eficaz la imposición religiosa, económica, etc. Los ejemplos abundan en la historia colonial. Por ejemplo es sabido como en 1610, los jesuitas instalados en el Cusco, realizarán una procesión del niño Jesús, ataviado con mascaypacha y atuendos incas. Eran pues, las recomendaciones del tercer Concilio Limense (1582-1583) en que los hijos de Loyola tendrán un papel protagónico y que otorgarán una importancia central al uso de las imágenes para la adquisición de la fe a "través de los sentidos" (Valenzuela 2006).

En ese sentido, cuatro aspectos (entre otros) explicarían las características que tomó la evangelización religiosa: 1) al reducir la población indígena en comunidades convirtiéndolos nuevamente en campesinos, los 
arrojó a los mismos fenómenos telúricos que alimentaron sus antiguas creencias, 2) al impedir la formación de un clero indígena, evangelizándolos en quechua, reavivó mitos y creencias primordiales que moldearán lo que después se vino en llamar el catolicismo andino, 3) como consecuencia de lo anterior, en una sociedad agraria y panteísta, le fue familiar (en un proceso de transferencias y de analogías) la imposición religiosa a través de ciertos signos como montañas, cuevas, oquedades, quebradas, ríos, lagunas y rocas y 4) la adopción del catolicismo fue una estrategia de inclusión del propio mundo indígena en la esfera de los colonizados. Esfuerzo que será bloqueado permanentemente por los Concilios Limenses, pues su adscripción completa al catolicismo, significaba simple y llanamente, la desaparición del indio (Estenssoro 2003).

Szemisnki habla en ese sentido, de la transformación de los nuevos significados que proveyeron los españoles: "La identificación vuelve a aparecer en la forma que parece Jesús en los Andes: en una peña, en un pozo, en una pared de adobe que perdura a los terremotos" (1992:96).

Es por ello, que casi todos los cristos andinos tienen un origen similar, pareciese que estos fundan las identidades locales de reducciones y pueblos. En Huamantanga (provincia de Canta) el cristo crucificado emerge de un manantial: "lagunilla en medio de la cual estaba levantada una piedra llamada guanca a la cual adoraba...este pueblo" "la piedra guanca era el dios Ticcllawacho" (Cajavilca 2005:21).

Aunque Arroyo (2008) ha deslizado la hipótesis de que estos "hermanos cristo" de la sierra central, serían en realidad wamanis con alcances regionales y vinculados a identidades socio-étnicas. Para ello se tendría que demostrar que las creencias nativas jerarquizan a las cristianas y que el congelamiento de esta última permitió reproducir "la religión andina". Atenuar al catolicismo, uno de los anclajes más importantes del sistema colonial parece ser un reflejo en cierta medida a-histórica.

La historia es similar a muchas versiones incluida la de Huayllay Grande: es la historia de los pintores y escultores que son encargados de pintar la imagen y que luego desaparecen misteriosamente una vez cumplida la tarea o también, ellos mismos aparecen representados. El caballo blanco de los personajes es reiterativo, también el deseo de la imagen de quedarse en el pueblo ante la posibilidad de ser trasladada a otra comunidad, como sucedió entre Huamantanga y Quipán.

En Muruhuay hay tres fechas de aparición del Señor. Según Lecaros (2001:17) están relacionadas con eventos o cataclismos sociales que tuvieron impacto en la región de Tarma: la rebelión de Juan Santos Atahualpa (1750) y la primera revuelta de Huarochirí, la de Túpac Amaru y la segunda algarada de Huarochirí (1790) y las "revueltas de la independencia" (1824). Aunque la autora no reporta algún asentamiento pre-hispánico en Abuelomarca o Willcamnarca donde aparece la imagen, si enfatiza a los manantiales y su carácter asocial y pagano.

En estas leyendas hay dos escenarios: uno natural y panteísta (rocas, cuevas, manantiales y montañas) y otro social (pintores y escultores españoles), que son revelados ante campesinos y pastores indígenas y validados por el párroco del lugar. En el primer escenario, es sintomático asociarlos a poblaciones o restos pre-hispánicos, para remarcar el tránsito de lo asocial/caótico a lo social/normalizado y de lo pagano/gentil a lo cristiano, como una estrategia de evangelización en los Andes centrales 


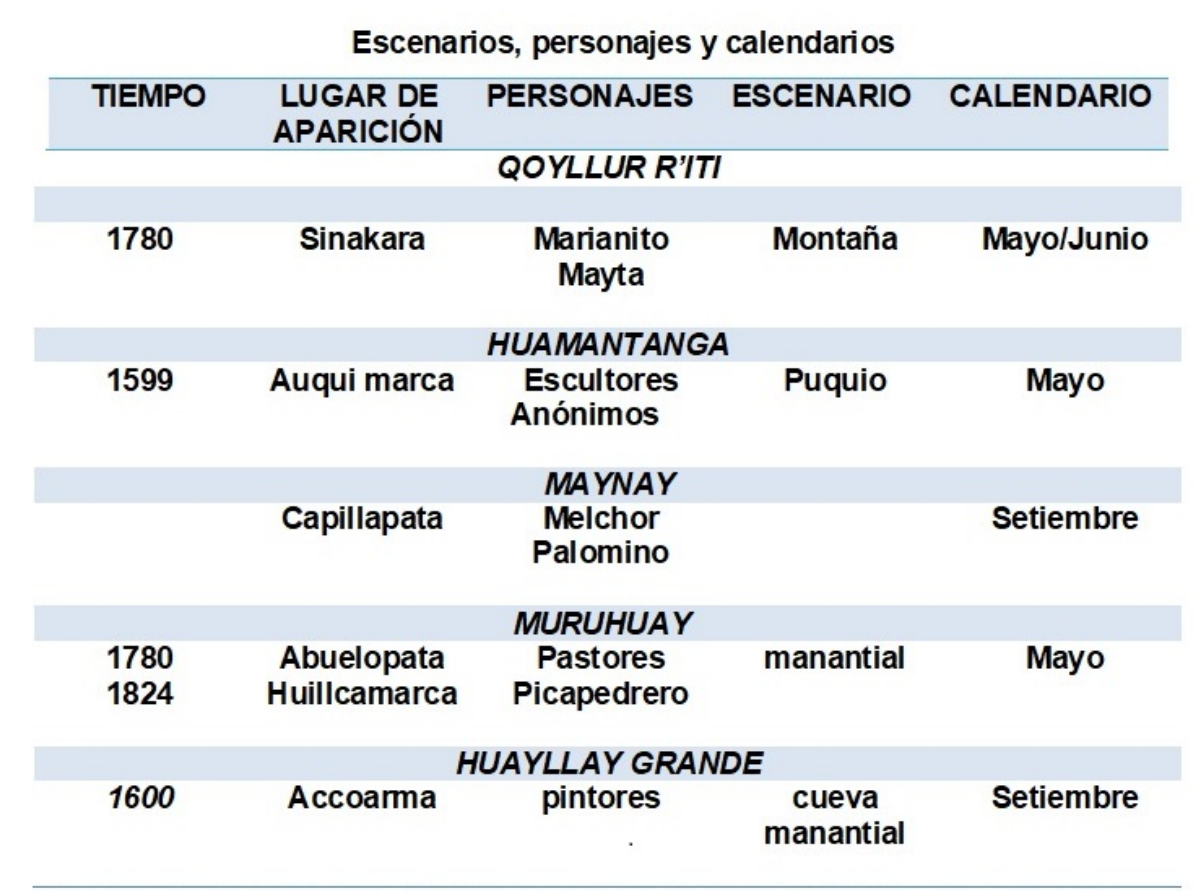

\section{CRISTOS DE LOS ANDES}

Fuentes: Qoyllur Riti (Poole 1988), Huamantanga (Cajavilca 2005), Muruhuay (Lecaros 2001), Huayllay Grande (Pastor Ibáñez, información personal 2014).

Como se podrá apreciar en el cuadro simple que presentamos, los cinco cristos tienen algunas constantes. En primer lugar, las imágenes han sido encontradas en parajes de la puna. Esta zona en la sociedad andina, es esencialmente a-social, masculina y "llacuaz", es decir salvaje. Sin embargo si bien la puna sólo está dedicada al cultivo de las papas y la crianza de la ganadería, sus crestas, si bien no tenían importancia económica, era un espacio cargado de ritualidad. Esto debió hacerse bien por la importancia de la puna, que albergan a los cerros tutelares o quizás, por la represión religiosa, pues los parajes solitarios eran ideales para las prácticas clandestinas no cristianas.

Así mismo, los personajes vinculados a los hallazgos o descubrimientos son mestizos o indios plenamente individuados. Esto no sólo por la necesaria hagiografía cristiana, sino también, para resaltar lo extraordinario de la esfera sagrada, muy lejana de la medianía del común de indios. Todos oscilan también, entre los meses "secos" y los "húmedos", los fríos de los calientes. Si bien son distantes en los ciclos agrícolas: siembra-cosecha; también son espacios comunes de celebración y de libertad sexual. Al encontrarse los extremos, se completa el círculo de la re-creación del mundo natural y social.

\section{RELIGIOSIDAD Y ESTRUCTURA SOCIAL}

En Huayllay Grande, los relatos escuchados sobre su aparición están referidos a una constante que respondió seguramente a estrategias pan-andinas de evangelización.

En uno:

1. La imagen aparece cerca del pueblo,

2. Los pueblos aledaños pretenden llevársela,

3. Fracasan en su intento debido a su exceso peso y,

4. la imagen se queda en el pueblo.

En la otra versión, la imagen es hallada en la cueva de Accoarma en la parte baja de la comunidad y casi a orillas del río Lircay. Un anciano "barbudo” comprometido en pintar la imagen de cristo es al final del relato, 
auto-representado como el crucificado. También está asociada a una fuente de agua que podría ser la paqarina del pueblo. No olvidemos que los ojos de agua, conectan el mundo subterráneo con la superficie social y están asociados a la fertilidad. En Canta y Huancavelica se encuentran con el o los artesanos en encrucijadas próximas al pueblo: Taro en Huamantanga o Jatun Sayhua en Huayllay.

Toda fiesta y ciclo ritual posee un sentido de renovación, garantiza el re-ordenamiento del mundo y echa a andar el cosmos expresado en la normalización del tiempo, los ciclos temporales y el de los grupos sociales involucrados (Bandelier 1969, Ladero 2004). Para que ello se lleve a cabo y posea "eficacia simbólica", tienen que existir introductores sociales, es decir, una jerarquía de cargos sociales y religiosos.

Además, una fiesta-santuario como es el Señor de Huayllay tiene una "geografía sagrada" es decir, un espacio que como una fuente irradiada también se constituye en escenario de contraprestaciones, de relaciones inter-étnicas y de articulación regional. Relaciona a campesinos de altura y de los valles, a ganaderos y a agricultores, a paisanos, clientes y compadres; y también reúne la especialización artesanal que era útil para reproducir la vida doméstica de un área campesina nada desdeñable.

A diferencia de la peregrinación a Muruhuay que gira alrededor de un santuario en cierto modo encapsulado, donde la variable espacial esta retraída por la carga social en una región como Tarma (con altos índices de desarrollo mercantil), donde el capital y el prestigio funcionan como vehículos de integración (Lecaros2001), en Huayllay Grande trajo aparejada una concurrida feria.

Aquí se operaba una doble dimensión: una colonial en que gravitaba en los centros urbanos articulados a la economía campesina como Huancavelica, Huanta o Lircay y de la otra, un área que podría reproducir categorías territoriales pre-hispánicas.

De un documento revisado y que estaba en poder de las autoridades de la comunidad, recabamos información de que posiblemente hasta el siglo XIX, los mayordomos elegidos eran españoles (en el sentido colonial del término)[3] y personas de "probidad" y de conocida "devoción".[4] En 1786 el mestizo Gabriel de Riveros figuraba como devoto del Señor Crucificado de Huayllay. Tal Gabriel de Riveros parece ser el mismo vinculado a una denuncia hecha en 1804 por las autoridades indígenas de San Pedro de Moya, casi en los límites de la Intendencia de Angaraes.

Este con otro mestizo, esteban Arana de Vilca (vecina a Moya) eran acusados de comprar trigo y cebada a la fuerza, para posteriormente venderlos en Huamanga. Registraban casa por casa aprovechando sus cargos de "recaudadores" y además "los afligía y extorsionaba sin piedad" (Favre 1983/85).

Una relación de los cargos de este Cristo y que abarca un lapso de 50 años, nos revela la importancia del prestigio social de estos mayordomos.

\begin{tabular}{|c|c|c}
\hline AÑO & MAYORDOMO & ORIGEN \\
\hline 1787 & Juan Bidalón & Español de Lircay \\
1788 & Gregorio Delgado & Español de Lircay \\
1789 & Marcelo de la Torre & Español \\
\hline 1795 & Toribio Chávez Tnte. Crnl. De Milicias & Español \\
\hline 1803 & Domingo de Arana & Criollo? \\
\hline 1820 & Celedonio Paredes & s.i. \\
\hline 1823 & José Manuel Durand & Criollo de Huancavelica \\
1825 & Cipriano Ludeña & Mestizo de Acobamba \\
1828 & José Manuel Raymundo & Criollo de Huancavelica \\
\hline 1850 & José Bargas & Mestizo de Lircay \\
\hline
\end{tabular}

Relación de los cargos

Fuente: Documentos de la comunidad de Huayllay Grande. (Plasencia 2016: 153) 
Sin embargo, para principios del siglo XX, los mayordomos y demás cargos de esta fiesta pasaron a ser indígenas lugareños. ¿Cómo pudo operarse este cambio? No tenemos los datos que den respuesta a nuestra pregunta. Pero si es cierto que los factores de identidad son relacionales y como tal, son móviles y polimorfos. Así esta peregrinación que privilegiaba un importante espacio mercantil (la minería, el arrieraje y haciendas adyacentes a Huancavelica) otorgaba a sus "pasantes" prestigio y los vinculaba a redes de poder más amplias. Además de que les otorgaban (a blancos y mestizos) estatus étnico en un escenario drásticamente escindido.

El reordenamiento de estos espacios en el siglo XX, como consecuencia de la llegada del ferrocarril a Huancavelica, la apertura de nuevas carreteras y la crisis terrateniente, hizo posiblemente que la fiesta en tan importante santuario, fuese abandonada paulatinamente por el grupos de propietarios. El esplendor de su festividad fue declinando y con ello el prestigio de "pasarla". Volviéndose un culto y una feria eminentemente campesina. La nueva fiesta patronal de Lircay centrada en la Virgen el Carmen, representaría ese importante cambio socio-religioso.

\section{RENOVANDO CiClos Y RITUALES}

El santuario corresponde a la iglesia del pueblo construida probablemente en 1620, es de una sola nave, cuyo eje se desarrolla paralelo a la plaza. Su hermoso frontispicio deja ver la influencia del barroco (del Busto 1989). El ciclo ritual del cristo lugareño comienza el 14 de setiembre, que es el equinoccio primaveral y la preparación de las siembras. Hay seis días de actividades rituales: (1) la víspera (2) el día grande (3) primer júbilo (4) segundo júbilo (5) primera bendición y (6) segunda bendición. Sin embargo en el nivel regional, el contexto del ciclo ritual para las comunidades es todavía una referencia importante de articulación vallepuna, graficada en el Mosoq Wata.

Esta última celebración, tiene que ver con la elección de los varayos en un trayecto que vincula el pueblo de Lircay (capital de la provincia), Carhuapata y la propia comunidad. En ella, una placa de plata es custodiada por la cofradía de mistis de Lircay, enfatizando de este modo, las relaciones de reciprocidad (pero también profundamente jerárquicas) entre dos conjuntos sociales. La ida a Lircay nos da una idea de esta relación además que el pueblo de Carhuapata (hoy comunidad campesina) era el anexo ganadero ("las punas de Guayllay”) que con la reforma agraria de los 70, se quebraría este patrón de complementariedad ecológica.

Otra ceremonia en la cual el cristo huayllino tiene condición de testigo es el Muyukuy, que se desarrolla en el viernes santo e involucra la presencia de un sacerdote y la obligación del mayordomo de pagar la misa. En esta ceremonia los mayordomos del Cristo, los varayos y el pueblo se reúnen. La palabra "muyukuy" en sí, tiene un sentido de cohesión comunal. La palabra significa literalmente "girar".

Por otra parte, recuerda el mito de origen de la comunidad. Además muyukupata es una nominalización del quechua muyuku con el sufijo pata, indicando borde o lugar. El muyu son los campos en donde los sistemas de propiedad comunal aún son usados. La reciprocidad se articula con la jerarquía y en ella se superponen distintos ciclos (rituales, los productivos y sociales), que garantizan la marcha de este pequeño universo.

\section{FUNDANDO IDENTIDADES SOCIO-ÉTNICAS}

Abercrombie (1992) ha señalado que la fiesta del carnaval de Oruro expresa las tenciones étnicas y las contradicciones de la ideología nacionalista en la Bolivia contemporánea. Aunque abusa del término de "poscolonialismo", acierta cuando dice que los distintos grupos "anómalos" por emergentes y poseídos de una "cultura de la conversión", tratan de lograr legitimidad participando en la organización y participación (superando su exclusión histórica) en tan importante festividad. Del mismo modo, parece haber ocurrido en los Andes centrales, las fiestas patronales incluidos los santuarios, aparte de sus símbolos y su complejo 
religioso, expresan de manera dramática las relaciones sociales y la dinámica de distintos sub-conjuntos sociales.[5]

En Moya (Huancavelica) los tres ayllus el de Qollana (indios), Chaupi (mestizos) y Allauca (mistis) poseían santos patrones separados, pero para el siglo XX, San Miguel es el santo que emerge y unifica a la comunidad. En Muquiyauyo (Jauja), indios y mestizos tenías sus santos y cofradías separadas y marcaban fronteras socio-étnicas, esto antes de la "gran transformación" que significará el trabajo asalariado en las minas y la generalización de la movilidad social (Adams 1959).

En Paucartambo (Cuzco) la Virgen del Carmen y del Rosario representan por un lado, la celebración de los vecinos de la capital provincial y del otro, el de las comunidades campesinas aledañas. En Laramate, situada en la frontera entre Ayacucho y Huancavelica, la virgen es encontrada en una laguna: "Al amanecer de un cierto día, en el centro de dicha laguna, apareció la Virgen del Rosario flotando encima de un mate burilado. Los hacendados de esa época, que dominaban a la población, eran las familias Castila, Soto y Gastelú, quienes obligaron a los indios del lugar que vivían en Ocaña, Belén Pata, Pablopata y San Judas para que levantaran una iglesia donde pudiera descansar dicha virgen" (Vallejo 2016: 195).

Los ayllus se legitiman con esta misma estrategia. Pareciese que en Andamarca (Ayacucho), las imágenes religiosas confirman los principios de jerarquía y competitividad de las comunidades (Ossio1977). La historiadora Ana Sánchez (1990) ha relatado los entretelones de la aparición y posterior devoción de una imagen de Concepción de María en Acoria (Angaraes) en 1688, en ese entonces en los términos de Huamanga. Temblores, visiones y confesiones de testigos que sólo pueden entenderse en el clima barroco de los Andes. En ese trajín, las autoridades coloniales obligaron a la población indígena a erigir iglesias y santuarios, como punto culminante de la cristianización americana (Marzal 1983).

\section{Conclusiones}

El cristo de Huayllay Grande hoy base fundamental de la identidad local y desasida ya, del poder regional, es un buen ejemplo de la construcción colonial de la religiosidad. Si bien en un primer momento (el decisivo siglo XVI) fue acomodada a la particularidad cultural de la sociedad indígena fue paulatinamente interferida por la evolución histórica de la sociedad a lo largo y ancho de los Andes centrales.

Los matices pre-cristianos y los ciclos de una sociedad agraria, fueron incorporados a los conflictos sociales y étnicos y que si bien, no alcanzó la envergadura del caso mexicano (Lafaye 1985), por lo menos fue cristalizándose en una especie de religiosidad popular que puede ofrecerse como el parapeto de resistencias y reclamos, pero también del afianzamiento del estado de cosas.

\section{Referencias Bibliográficas}

Abercrombie, Th. (1992). La fiesta del carnaval en Oruro: Clase, etnicidad y nacionalismo en la danza folklórica. En Revista Andina 10 (2):279-352.

Acosta de, J. (1986) [1590] Historia natural y moral de las Indias. Madrid: Historia 16.

Alcedo y Herrera, A. (1967) [1786/89]. Diccionario de la Indias Occidentales o América. Madrid: Biblioteca de Autores Españoles BAE.

Adams, R. (1959). A Community in the Andes. Problems and Progress in Muquiyauyo. Seattle: University of Washington Press

Arroyo, S. (2008). Culto a los Hermanos Cristo. Sistema Religioso Andino y cristiano: redes y formas culturales del poder en los Andes. Lima: UNMSM.

Bandelier, G. (1969). Antropología Política. Madrid: Península.

Bueno, C. (1951). Geografía del Perú Virreinal, siglo XVIII. Lima: UNMSM. Edición de C.D.Valcárcel. 
Busto del J.A. (1989) La arquitectura barroca de Huancavelica. En Boletín del Instituto Riva -Agüero (16). Cajavilca, L. (2005). Santísimo Cristo de Huamantanga. Lima: Casa de la Cultura Pedro Villar Córdova.

Esstensoro, J.C. (2003). Del paganismo a la santidad. La incorporación de los indios del Perú al catolicismo, 1532-1750. Lima: IFEA/PUCP/IRA.

Favre, H. (1983/85) "El mundo andino en tiempos de Bolívar: los Asto entre 1780 y 1830" en Revista del Museo Nacional (47):259-271.

Gil Calvo, E. (1991). Estado de Fiesta. Feria, toro, corte y circo. Madrid: Espasa-Calpe.

Jiménez de la Espada, M. (1965). Relaciones Geográficas de Indias-Perú. Madrid: BAE.

Ladero, M.A. (2004). Las fiestas en la cultura medieval. Barcelona: Areté.

Lafaye, J. (1985). Quetzalcoátl y Guadalupe: la conformación de la conciencia nacional de México. México, FCE.

Lecaros, A.T. (2001). Los Peregrinos del Señor de Muruhuay. Espacio, culto e identidad en los Andes. Tesis de doctorado. Berlín: Universidad Libre.

Marzal, M. (1983). La transformación religiosa peruana. Lima: PUCP.

Ossio, J.M. (1977). Los mitos de origen en la comunidad de Andamarca, en Allpanchis (10): 105-113.

Plasencia, R. (2016). Comunidades indígenas de Huancavelica: etnicidad, conflicto y autonomía cultural en el Perú central: 1880-1980. Tesis de Doctor, Departamento de Antropología Social, Universidad de Sevilla.

Poole, D. (1988). Entre el milagro y la mercancía: Qoyllur Riti, en Márgenes (4).

Sánchez, A. (1990). La aparición de la Virgen en la doctrina de Acoria (Huamanga, 1688) en Revista Española de Antropología Americana (20): 105-134,

Szeminski, J. (1992). La transformación de los significados religiosos en los Andes centrales (siglos XVI-XVIII) en De Palabra y Obra en el Nuevo Mundo, Vol.3. La formación del otro. Gossen y Klor de Alva edit. Madrid: Siglo XXI.

Valenzuela, J. (2006). Ambigüedades de la imagen en la cristianización del Perú: Trento, los jesuitas y el Tercer Concilio en Investigaciones Sociales UNMSM (17): 491-503.

Vallejo, P. (2016). A propósito del nombre de Laramate, en Alteritas. Ayacucho: UNSCH.

\section{Notas}

[1] "En Huayllay hay un crucifijo muy milagroso y venerado de todas aquellas comarcas"

[2] Huayllay Grande o Hatun Huayllay, es una antigua reducción que perteneció al curato de Lircay, en el corregimiento de Angaraes, fue una de las más importantes de la región por estar cercana a las minas de Huancavelica. Creada como distrito en 1941, pertenece a la provincia de Angaraes, departamento de Huancavelica

[3] En la República de Españoles, eran "españoles" (peninsulares, indios nobles, criollos y mestizos) los que sencillamente no pagaban tributo, la adscripción socio-étnica tenía entre otros aspectos un fuerte ingrediente fiscal. A ellos, se agregaban condiciones como la propiedad y la residencia urbana. En muchos padrones tardo-coloniales aparecen con el Don y el estatus se heredaba por vía paterna y masculina, siempre y cuando los matrimonios fuesen legítimos.

[4] En 1689 se crea la cofradía de españoles del Cristo de Humantanga. Cajavilca en su estudio, tiene el acierto de publicar los autos de su fundación.

[5] Enrique Gil (1991) en un expresivo ensayo clasifica a las fiestas de "libertarias", "comunitarias" y "autoritarias". Estas últimas "transforma a individuos libres e independientes en sujetos a una pública comunidad interpersonal, que goza de autoridad moral sobre ellos. Esto hace que las personas aprendan a amar su sujeción a la autoridad pública" (153). La fiesta del Señor de Huayllay, puede tener el tinte de las tres modalidades, pero también evolucionar de una hacia las otras.

(C) Los autores otorgan el permiso a compartir y usar su trabajo manteniendo la autoría del mismo.

CC BY-NC

INFORMACIÓN ADICIONAL 
Datos del autor: Rommel Humberto Plasencia Soto. Peruano. Docente e Investigador adscrito al Departamento de Antropología, Facultad de Ciencias Sociales, UNMSM. Licenciado por la UNCP. Magister en Antropología, Pontificia Universidad Católica del Perú, Doctor por el Departamento de Antropología Social, Universidad de Sevilla. 